\title{
Depletion of Reactive Advanced Glycation Endproducts from Diabetic Uremic Sera Using a Lysozyme-linked Matrix
}

\author{
Tomoko Mitsuhashi, ${ }^{\star}$ Yong Ming Li, ${ }^{\star}$ Steven Fishbane, ${ }^{\ddagger}$ and Helen Vlassara* \\ *The Picower Institute for Medical Research, Manhasset, New York 11030; and ${ }^{\ddagger}$ Winthrop University Hospital, Mineola, New York 11501
}

\begin{abstract}
Diabetic uremic sera contain excessive amounts of reactive advanced glycation endproducts (AGEs), which accelerate the vasculopathy of diabetes and end-stage renal disease. To capture in vivo-derived toxic AGEs, high affinity AGE-binding protein lysozyme (LZ) was linked to a Sepharose 4B matrix. Initial studies showed that $>80 \%$ of ${ }^{125}$ I-AGE-BSA was retained by the LZ matrix, compared with $<10 \%$ retained by a control matrix. More than $60 \%$ of AGE-lysine was captured by the LZ matrix, and the LZ-bound fraction retained immunoreactivity and cross-linking activity, but had little intrinsic fluorescence $(370 / 440 \mathrm{~nm})$. After passage through the $\mathrm{LZ}$ matrix, AGE levels in diabetic sera $(0.37 \pm 0.04 \mathrm{U} / \mathrm{mg})$ were significantly reduced to a level $(0.09 \pm 0.01 \mathrm{U} / \mathrm{mg} ; n=$ 10; $P<0.0001)$ comparable with the level of normal human serum, whereas total protein absorption was $<3 \%$. The AGE-enriched serum fraction exhibited cross-linking activity, which was completely prevented by aminoguanidine. Among numerous LZ-bound proteins in diabetic uremic sera, three major proteins "susceptible" to AGE modification were identified: the immunoglobulin $\mathrm{G}$ light chain, apolipoprotein $\mathrm{J}$ (clusterin/SP-40,40), and the complement $3 \mathrm{~b} \beta$ chain. These findings indicate that the LZ-linked AGE affinity column may serve as an efficient method for the depletion of toxic AGEs from sera, including specific AGE-modified proteins that may be linked to altered immunity, lipoprotein metabolism, and accelerated vasculopathy in renal failure patients with or without diabetes. (J. Clin. Invest. 1997. 100:847854.) Key words: diabetic renal failure • hemodialysis • lysozyme $\cdot$ AGE affinity column • glycotoxin
\end{abstract}

\section{Introduction}

Advanced glycation endproducts (AGEs) ${ }^{1}$ comprise a heterogeneous class of posttransitional modifications that form spontaneously in vivo as well as in vitro via nonenzymatic reactions

Address correspondence to Tomoko Mitsuhashi, M.D., Ph.D., The Picower Institute for Medical Research, 350 Community Drive, Manhasset, NY 11030. Phone: 516-562-9556; FAX: 516-562-9516; E-mail: vlassara.lab@picower.edu

Received for publication 6 December 1996 and accepted in revised form 19 May 1997.

1. Abbreviations used in this paper: AG, aminoguanidine; AGE, advanced glycation endproduct; CML, carboxymethyllysine; ESRD, endstage renal disease; LF, lactoferrin; LZ, lysozyme; NHS, normal human serum; RT, room temperature.

J. Clin. Invest.

(c) The American Society for Clinical Investigation, Inc. 0021-9738/97/08/0847/08 \$2.00

Volume 100, Number 4, August 1997, 847-854

http://www.jci.org between reducing sugars and proteins (1). These interactions lead to the formation of chemically reactive products (glycotoxins; reference 2) that readily form intra- and intermolecular covalent cross-links. A large number of studies suggest that the long term pathological sequelae of diabetes and chronic renal failure result from the accumulation of tissue macromolecules that have been progressively modified by AGEs $(3,4)$. Although the predominant pathogenic AGE structure present in vivo remains unknown, AGE-specific immunochemical methods have shown that tissues from diabetic animals and patients have significantly elevated levels of AGEs $(5,6,8$, 9 ), and that serum AGE levels are significantly increased in diabetic and nondiabetic patients with end-stage renal disease (ESRD) $(6,7)$.

Lysozyme (LZ) and lactoferrin (LF) are two important naturally occurring antibacterial defense proteins found in saliva, nasal secretions, mucus, serum, and in the lysosomes of neutrophils and macrophages (10-13). We have shown previously that LZ and LF bind AGEs noncovalently, and that LZ binds AGEs with high affinity $\left(K_{\mathrm{d}} 50 \mathrm{nM}\right)(14)$. After mapping the AGE-binding domains of LZ and LF, we identified a conserved AGE-binding cysteine-bounded domain that is shared by LZ, LF, and other antimicrobial proteins (14). Furthermore, we have shown that LZ enhances the uptake and degradation of AGE proteins by macrophages via the AGE-receptor pathway (15). Our recent studies suggest that the binding of LZ to AGEs may play a critical role in AGE removal by serving as an opsonizing factor for AGEs to facilitate their in vivo turnover (16), and that the increased incidence of infection in diabetic patients may be attributed to the inactivation of the antibacterial activity of LZ as a result of AGE binding (14). Among the soluble AGE-binding proteins identified to date, LZ has the highest affinity for AGEs (14). Taking advantage of this specific interaction, we proposed to use an AGEaffinity LZ matrix, prepared from LZ conjugated to Sepharose $4 \mathrm{~B}$, to deplete AGEs from the sera of diabetic patients with ESRD. In this report, we studied the binding of both in vitroand in vivo-derived AGEs to the LZ matrix and identified three major AGE proteins in serum that are susceptible to AGE modification.

\section{Methods}

Chemicals and reagents. Bovine serum albumin, bovine pancreatic RNase, chicken hen egg white LZ, bovine fibronectin 30-kD fragment, D-glucose, L-lysine, cyanogen bromide-activated Sepharose $4 \mathrm{~B}$, and $p$-nitrophenyl phosphate tablets were purchased from Sigma Chemical Co. (St. Louis, MO). Sodium ${ }^{125}$ I-iodide was from DuPontMerck Pharmaceutical Co. (Wilmington, DE). Aminoguanidine hydrochloride (AG) was from Alteon Inc. (Ramsey, NJ). An anti-AGERNase antiserum produced in a female New Zealand White rabbit characterized as previously described (6) was used for immunoassay and immunoblotting. Free or BSA-bound carboxymethyllysine (CML) and pentosidine were courteously provided by Dr. V.M. Monnier (Case Western Reserve University, Cleveland, $\mathrm{OH}$ ). 
Preparation of AGE-modified proteins. AGE-modified BSA (AGE-BSA) and RNase (AGE-RNase) were prepared as previously described (6). Briefly, each protein was incubated under sterile conditions with $0.5 \mathrm{M} \mathrm{D}$-glucose in $0.2 \mathrm{M}$ phosphate buffer, $\mathrm{pH} 7.4$, at $37^{\circ} \mathrm{C}$ for $8 \mathrm{wk}$, and then low molecular weight reactants and glucose were removed by dialysis (10-kD cut-off) against phosphate-buffered saline, $\mathrm{pH}$ 7.4. To prepare AGE-lysine, $0.2 \mathrm{M}$ L-lysine was incubated with $0.5 \mathrm{M} \mathrm{D}$-glucose in $0.2 \mathrm{M}$ phosphate buffer, $\mathrm{pH} 7.4$, at $37^{\circ} \mathrm{C}$ for $8 \mathrm{wk}$, and desalted using a PD-10 column (Sephadex G-25 M; Pharmacia LKB Biotechnology, Uppsala, Sweden). The degree of AGE-modification of these proteins was determined by a competitive AGEELISA as described previously $(6,17)$.

Human serum samples. Serum samples were obtained from $10 \mathrm{di}-$ abetic patients with renal failure undergoing hemodialysis (age, $60 \pm 9.8 \mathrm{yr}$; duration of diabetes, $15 \pm 5.9 \mathrm{yr}$; duration of dialysis, $\left.2.8 \pm 2.0 \mathrm{yr} ; \mathrm{HbA}_{1 \mathrm{c}}, 8.5 \pm 1.67 \%\right)$ and from four healthy individuals (age, $33 \pm 5.0 \mathrm{yr} ; \mathrm{HbA}_{1 \mathrm{c}}, 4.7 \pm 0.14 \%$ ). Informed consent and assent were obtained from all study participants. Samples were stored at $-70^{\circ} \mathrm{C}$ before analysis.

Iodination of proteins. AGE-BSA, BSA, and fibronectin were iodinated using Iodo-Beads (Pierce, Rockford, IL). The free iodine in each sample was $<10 \%$ as determined by trichloroacetic acid precipitation. Specific activities were $\sim 3,000 \mathrm{cpm} / \mathrm{ng}$ for AGE-BSA and $\mathrm{BSA}$, and $5,000 \mathrm{cpm} / \mathrm{ng}$ for fibronectin.

Isolation of AGE-modified serum proteins using an LZ-linked Sepharose $4 B$ column. To construct an LZ-linked matrix column (LZ column), LZ was conjugated to cyanogen bromide-activated Sepharose $4 \mathrm{~B}$ beads according to the manufacturer's instructions. A control column (CL column) was constructed by conjugating BSA to Sepharose $4 \mathrm{~B}$ beads following the same procedure. To test the binding of in vitro-modified AGEs, ${ }^{125}$ I-AGE-BSA or ${ }^{125}$ I-BSA $(\sim 3,000,000 \mathrm{cpm} /$ column) was loaded onto either an LZ or a CL column (bed volume, $0.5 \mathrm{ml}$ each). For the binding of in vivo-formed AGEs, 1-ml samples of sera were diluted 1:5 with PBS just before loading on LZ columns (bed volume, $2 \mathrm{ml}$ ). After loading the diluted serum samples and collecting pass-through fractions, LZ columns were washed extensively. Then the LZ-bound fractions $(0.5 \mathrm{ml}$ per fraction) were eluted with $0.1 \mathrm{~N} \mathrm{NaOH}$, and neutralized immediately with $\mathrm{HCl}$ for the following experiments. The brief $\mathrm{NaOH}$ exposure did not alter the detectability of AGEs in samples by ELISA described below. The protein concentrations of eluted LZ-bound fractions were determined by the method of Lowry et al. (18).

Immunoassay. A competitive AGE-ELISA using anti-AGERNase rabbit antiserum was employed to measure AGEs in fractions eluted from the LZ column. The procedure was described previously $(6,17)$ and AGE units were standardized by the normal human serum (NHS) method (17). Briefly, 96-well EIA/RIA plates (Costar Corp., Cambridge, MA) were coated with $100 \mu \mathrm{l} / \mathrm{well}$ of $3 \mu \mathrm{g} / \mathrm{ml}$ AGE-BSA in coating buffer ( $0.1 \mathrm{M}$ sodium bicarbonate, $\mathrm{pH}$ 9.6) overnight at $4^{\circ} \mathrm{C}$. Wells were washed three times with $150 \mu$ l of washing buffer (PBS, $0.05 \%$ Tween-20), and then blocked with $100 \mu$ l of SuperBlock $^{\mathrm{TM}}$ blocking buffer in PBS (Pierce) at room temperature (RT) for $1 \mathrm{~h}$. After three rinses, $50 \mu \mathrm{l}$ of competing antigen was added, followed by $50 \mu \mathrm{l}$ of anti-AGE antibody $(1: 4,000)$ in dilution buffer containing 2\% normal goat serum (GIBCO-BRL, Gaithersburg, MD). Plates were incubated at RT for $2 \mathrm{~h}$ with gentle agitation. Wells were then rinsed three times, followed by the addition of $100 \mu \mathrm{l}$ alkaline phosphatase-conjugated anti-rabbit IgG (affinity purified) (Boehringer Mannheim Biochemicals, Indianapolis, IN) $(1: 3,000)$ in dilution buffer with $1 \%$ normal goat serum. Plates were then incubated at $37^{\circ} \mathrm{C}$ for $1 \mathrm{~h}$. After rinsing six times, $100 \mu \mathrm{l}$ of $p$-nitrophenyl phosphate substrate was added to each well. Optical density at $405 \mathrm{~nm}$ was determined by an ELISA reader (EL309; Bio-Tek Instruments, Inc., Burlington, VT) after $30 \mathrm{~min}$. Results were expressed as $\mathrm{B} / \mathrm{B}_{0}$, calculated as (experimental OD-background OD [i.e., no antibody])/ (total OD [i.e., no competitor]-background OD). One AGE unit is defined as the mean percent inhibition that results from 1:5 diluted NHS $(n=34)$ in the competitive ELISA (17). Our current standard
AGE-BSA is 0.38 AGE U/ $\mu$ g BSA using the anti-AGE RNase antiserum. The AGE-BSA was used as a competing antigen to generate an AGE standard curve (0.1-100 AGE U/ml). Sample AGE values were calculated from a linear regression of the standard curve.

Immunoassays for CML and pentosidine were performed in a similar manner as described above using specific antibodies and synthetic CML and pentosidine as standards, respectively.

Fluorescence assay. Fluorescence (Ex $370 \mathrm{~nm} / \mathrm{Em} 440 \mathrm{~nm}$ ) was measured with a luminescence spectrometer (LS50B; Perkin-Elmer Corp., Norwalk, CT).

$S D S-P A G E$ and immunoblotting. LZ-bound serum proteins were heated at $95^{\circ} \mathrm{C}$ for $5 \mathrm{~min}$ in reducing SDS loading buffer $(60 \% 4 \times$ loading buffer [0.4\% SDS, $0.1 \mathrm{M}$ Tris base, $0.768 \mathrm{M}$ glycine], $40 \%$ glycerol, and containing 4\% 2-mercaptoethanol) and loaded on a Tris-glycine gradient gel (4-20\%) (Bio-Rad Laboratories, Hercules, CA) as described (19). Separated proteins were transferred to a nitrocellulose membrane (Schleicher \& Schuell, Inc., Keene, NH), and then blocked with $5 \%$ dry milk in washing buffer (PBS with $0.05 \%$ Tween-20) at RT for $1 \mathrm{~h}$ with gentle agitation. After rinsing with washing buffer, the membrane was incubated with anti-AGE-RNase antiserum $(1: 1,000)$ at RT for $1 \mathrm{~h}$ with gentle agitation. The membrane was then rinsed with washing buffer and incubated with horseradish peroxidase-conjugated donkey anti-rabbit IgG (affinity purified) (Amersham Corp., Arlington Heights, IL) $(1: 10,000)$ at RT for $1 \mathrm{~h}$ with gentle agitation. After washing, the membrane was reacted with Super Signal ${ }^{\mathrm{TM}}$ (Pierce) at RT for $3 \mathrm{~min}$ and exposed to X-Omat AR film (Eastman Kodak Co., Rochester, NY) to record chemiluminescence.

Cross-linked complex formation assay. Samples were incubated with ${ }^{125}$ I-fibronectin 30-kD fragment for $1-7 \mathrm{~d}$ with $0.02 \% \mathrm{NaN}_{3}, 1 \mathrm{mM}$ PMSF, and $1 \mathrm{mM}$ EDTA for prevention of bacterial growth and degradation of proteins, with or without $2 \%(181 \mathrm{mM}) \mathrm{AG}$. The proteins were separated by reducing SDS-PAGE (4-20\% gradient Tris-glycine gels), and after drying the gels, high molecular weight complex formation was visualized by autoradiography.

$\mathrm{NH}_{2}$-terminal microsequencing of LZ-purified serum proteins. After loading on a reducing SDS-PAGE gel (12\% Tris-glycine) and transfer to an Immobilon-P Transfer Membrane (Millipore Corp., Bedford, MA) with CAPS (3-[cyclohexylamino]-1-propanesulfonic acid) transfer buffer as described (20), LZ-purified proteins were stained with amido black. Three major bands corresponding to $\sim 25,40$, and $80 \mathrm{kD}$ were cut out and subjected to $\mathrm{NH}_{2}$-terminal microsequencing (21). Protein databases (Lasergene; Protein Data and Swiss-Prot 31) for a homology search were from DNA Star (Madison, WI).

Statistical analysis. Analysis of variance and Student's $t$ test were used as appropriate to analyze differences between the groups. $P<$ 0.05 was considered significant.

\section{Results}

To evaluate the binding efficiency of LZ matrix for both in vitro- and in vivo-derived AGEs, the initial studies were performed using the labeled in vitro AGE-modified protein ${ }^{125} \mathrm{I}$ AGE-BSA and control ${ }^{125}$ I-BSA. More than $80 \%$ of the loaded ${ }^{125}$ I-AGE-BSA bound to the LZ column and was readily eluted with $0.1 \mathrm{~N} \mathrm{NaOH}$, whereas $<10 \%$ of ${ }^{125}$ I-BSA bound (Fig. 1). Similarly, when ${ }^{125} \mathrm{I}-\mathrm{AGE}-\mathrm{BSA}$ was loaded onto a CL column, $<10 \%$ of the ${ }^{125}$ I-AGE-BSA bound and eluted with $\mathrm{NaOH}$ (data not shown). These data suggested that binding to the LZ column is both AGE specific and noncovalent.

Next, we correlated the extent of column binding of AGElysine with the cross-linking activity of the fractions. Of the AGE-lysine loaded on an LZ column, the NaOH-eluted material represented $78 \%$ as measured by AGE-ELISA, but only $12 \%$ as measured by fluorescence (Fig. $2 A$ ). As shown by re- 


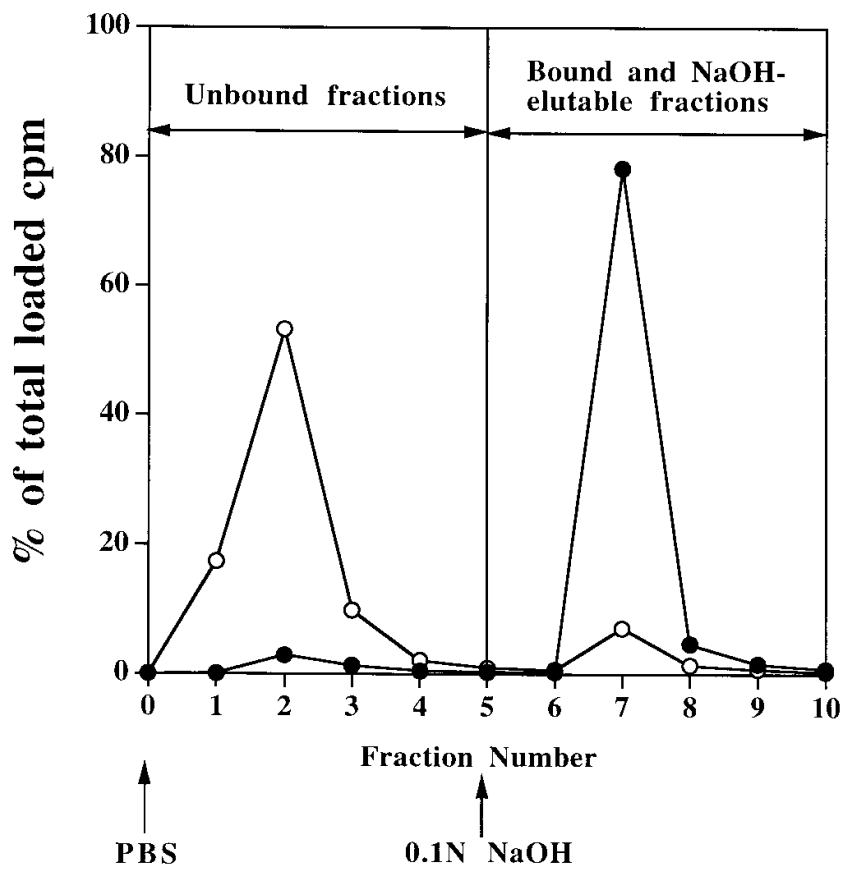

Figure 1. Protein binding to LZ matrix is AGE specific. ${ }^{125} \mathrm{I}$-AGEBSA $(\bullet)$ or ${ }^{125}$ I-BSA $(O)(1 \mu \mathrm{g}$, specific activity $3,000 \mathrm{cpm} / \mathrm{ng})$ was loaded onto LZ-linked Sepharose matrix columns $(0.5 \mathrm{ml})$. LZ columns were washed with PBS, and LZ-bound fractions were eluted with $0.1 \mathrm{~N} \mathrm{NaOH}$. Data are expressed as a percentage of total counts per minute loaded.

ducing SDS-PAGE after incubation with ${ }^{125}$ I-fibronectin (Fig. 2 B), AGE-lysine showed high molecular weight complex formation, and the LZ-bound fraction exhibited a large amount of cross-linking activity compared with the pass-through fraction. The cross-linked complexes formed in a time-dependent manner, and coincubation with $2 \%$ AG completely inhibited

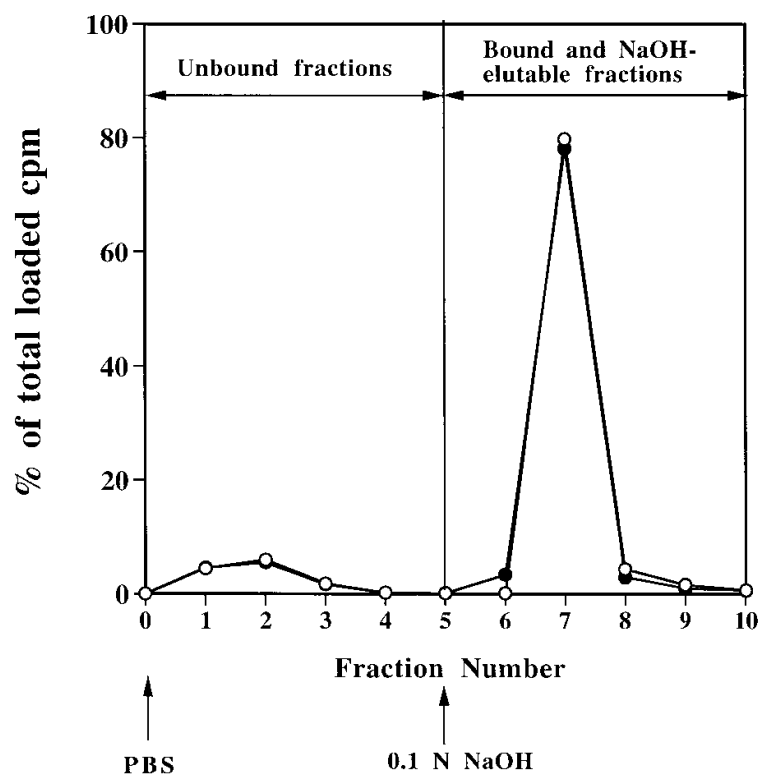

Figure 3. Binding of ${ }^{125} \mathrm{I}$-AGE-BSA to the LZ column is not affected by NHS. ${ }^{125}$ I-AGE-BSA was loaded onto the LZ column with $(\bullet)$ or without $(\bigcirc)$ 1:5 diluted NHS. LZ columns were washed with PBS, and LZ-bound fractions were eluted with $0.1 \mathrm{~N} \mathrm{NaOH}$. Data are expressed as a percentage of total counts per minute loaded.

this reaction. Taken together, these data indicated that the LZbound fraction retained a significant amount of immunoreactivity and cross-linking activity of the material applied to the column, but had very low fluorescence intensity.

We also tested whether the LZ column binds the structurally identified AGEs, CML and pentosidine. Before and after passing free or BSA-bound CML or pentosidine over an LZ column, the levels of CML or pentosidine in unbound fractions was measured using ELISA specific to CML or pentosidine,
A

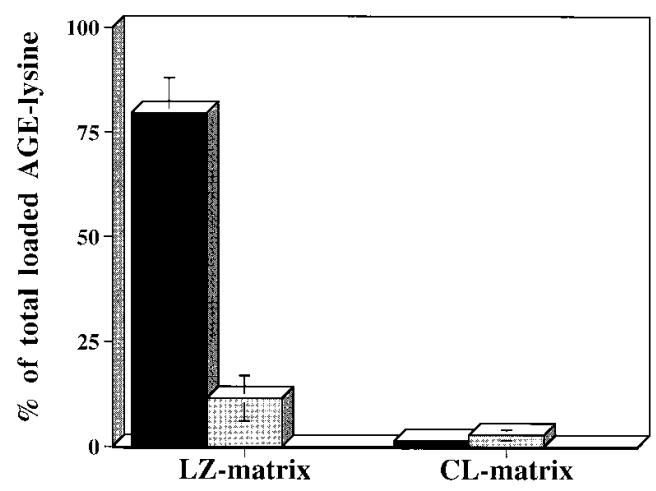

B

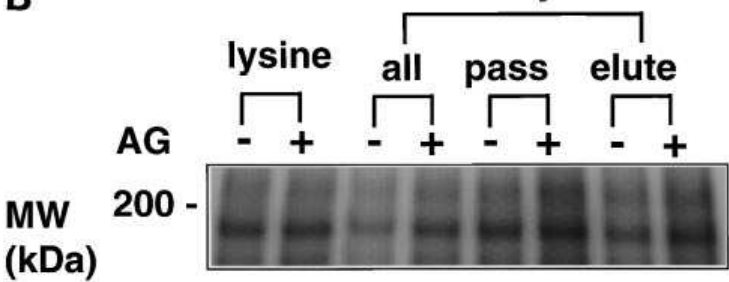

\section{Incubation time (day)}

1

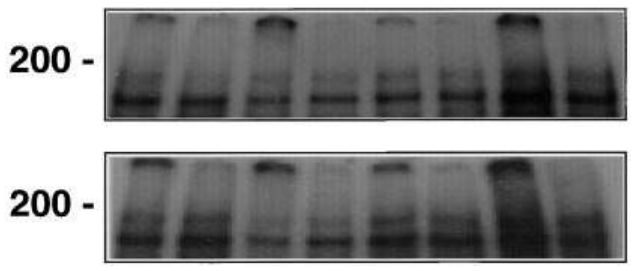

3

7

Figure 2. Lysozyme binds immunoreactive and cross-linking AGE moieties present in AGE-lysine. Desalted AGE-lysine was passed over either an LZ- or a CL-matrix column. (A) AGE immunoreactivity (black bar) and fluorescence $(370 / 440 \mathrm{~nm})($ gray bar) were determined in the combined bound and combined $\mathrm{NaOH}$-elutable fractions from each column. Data are expressed as a percentage of total loaded AGE-lysine (mean \pm SD). (B) Reducing SDS-PAGE of ${ }^{125}$ I-fibronectin incubated at $37^{\circ} \mathrm{C}$ for $1-7 \mathrm{~d}$ with lanes 1 and 2 , lysine; lanes 3 and 4 , desalted pre-LZ column AGE-lysine; lanes 5 and 6 , the pass-through fraction of AGE-lysine from the LZ column; and lanes 7 and 8 , the bound fraction of AGElysine eluted from the LZ column. Lanes 2, 4, 6, and 8 also include aminoguanidine $(A G)$. 
A

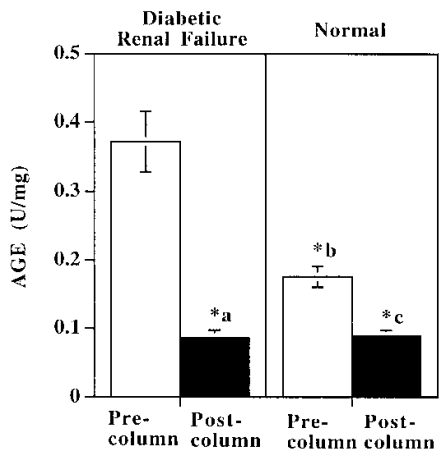

B

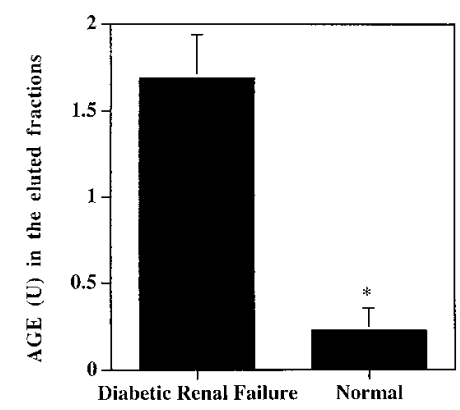

Figure 4. The LZ column effectively depletes serum AGEs. Sera from normal or diabetic patients with renal failure were diluted 1:5 with PBS and loaded onto an LZ column (2-ml matrix). (A) AGE levels determined by AGE-specific ELISA in serum samples before (open bars) and after (closed bars) passage through the LZ columns. AGE levels are expressed as mean \pm SEM AGE in units per milligram. *a: $P<0.0001$ vs. precolumn of diabetic renal failure; *b: $P<$ 0.05 vs. precolumn of diabetic renal failure; and $*$ c: $P<0.005$ vs. precolumn of normal. (B) AGE levels in the fractions that are LZ bound, eluted with $0.1 \mathrm{~N} \mathrm{NaOH}$, and neutralized. AGE levels in combined fractions from diabetic patients with ESRD and from normal individuals determined by AGE-specific ELISA, are expressed as mean \pm SEM AGE in units. ${ }^{*} P<0.005$ vs. diabetic renal failure.

respectively. No binding of free or protein-bound CML or pentosidine to the LZ column occurred.

To ultimately use the LZ column to capture serum AGEs, we next tested whether serum proteins affect the binding of AGEs to the LZ column. ${ }^{125}$ I-AGE-BSA was loaded onto an LZ column with or without 1:5 diluted NHS. As shown in Fig. 3 , the binding and elution profile of ${ }^{125}$ I-AGE-BSA with NHS was very similar to the profile without NHS. This indicated that the binding of AGEs to the LZ column was not affected by proteins present in human serum.

Based on the above observations, we investigated next whether the LZ column could deplete immunoreactive AGEs from the serum of diabetic patients with ESRD. The LZ column removed $77 \%$ of the in vivo-derived AGEs $(0.37 \pm 0.04 \mathrm{U} / \mathrm{mg})$, resulting in serum AGE levels $(0.09 \pm 0.01 \mathrm{U} / \mathrm{mg} ; n=10 ; P<$ 0.0001) comparable with that in NHS (Fig. $4 A$ ), whereas total protein absorption by the LZ column was $<3 \%$ (data not shown). The amount of AGEs in the $\mathrm{NaOH}$-eluted fractions from the sera of diabetic renal failure patients was approximately eight times greater than that from NHS (Fig. 4B).

Reducing SDS-PAGE and immunoblotting with anti-AGERNase antiserum were used to identify the AGE-modified proteins in sera bound by the LZ column and eluted with $\mathrm{NaOH}$. LZ-purified serum AGE proteins from nine diabetic patients with ESRD revealed numerous bands with various molecular weights, although the protein profile was quite distinct from that of whole serum (Fig. $5 A$ ). Several bands were stained by anti-AGE-RNase antiserum, and the intensity of some of these bands differed among patients (Fig. $5 B$ ).
A

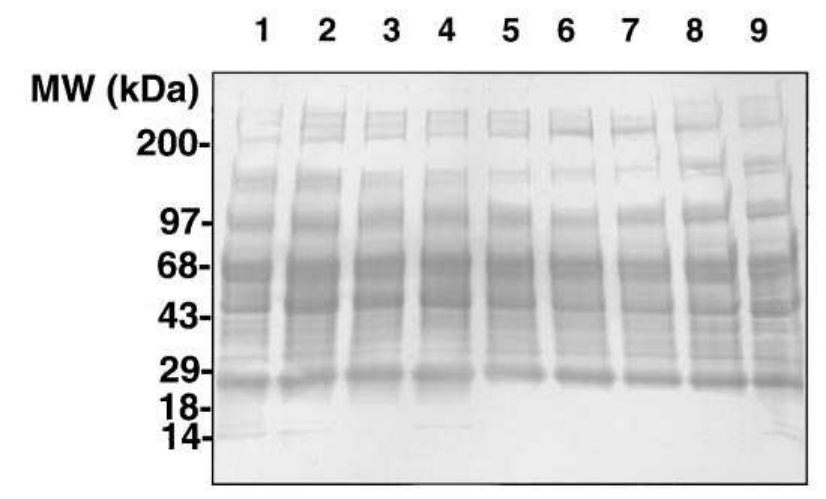

B

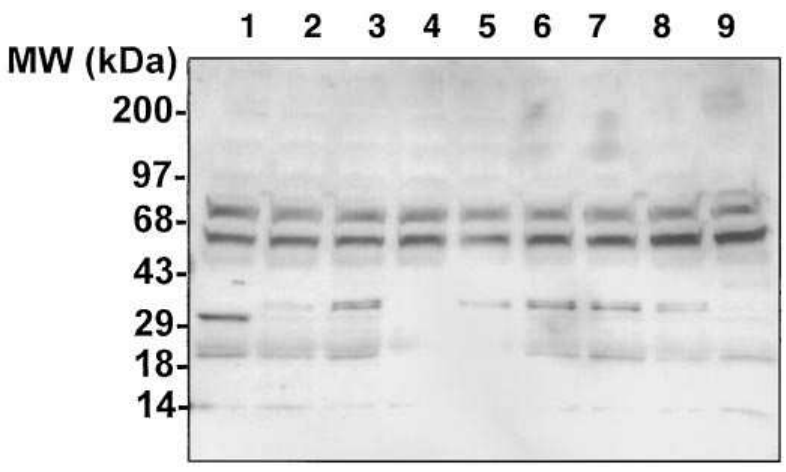

Figure 5. SDS-PAGE $(A)$ and immunoblot $(B)$ of LZ-bound serum AGEs from diabetic patients with renal failure. Isolation of LZbound serum AGEs and SDS-PAGE were performed as described in Methods. After transfer to a nitrocellulose membrane, immunoblotting was performed using anti-AGE-RNase as a primary antibody. (Lanes 1-9) LZ-bound and eluted serum AGEs from nine diabetic patients with ESRD.

To determine whether serum AGE proteins eluted with $\mathrm{NaOH}$ from an LZ column have cross-linking activity, ${ }^{125} \mathrm{I}-$ fibronectin was incubated at $37^{\circ} \mathrm{C}$ for $1-7 \mathrm{~d}$ with either native human IgG, in vitro-modified AGE-BSA, or LZ-purified AGE proteins from two patients with or without $2 \%$ AG. As shown in Fig. 6, AGE-BSA cross-linked with fibronectin in a timedependent manner; high molecular weight complex formation was effectively inhibited by coincubation with AG. LZ-purified serum AGE proteins from two patients showed a time-dependent, extensive cross-linking with fibronectin, and AG completely inhibited this reaction. In contrast, native human IgG, which exhibited nondetectable immunoreactive AGE levels, showed minimal cross-linking activity evident only at day 7 .

To identify the major proteins that are susceptible to AGE modification in vivo, we isolated several proteins from diabetic serum that showed high levels of AGE immunoreactivity, and identified the amino acid sequences of three of these proteins by microsequencing. As shown in Fig. 7, a homology search in 


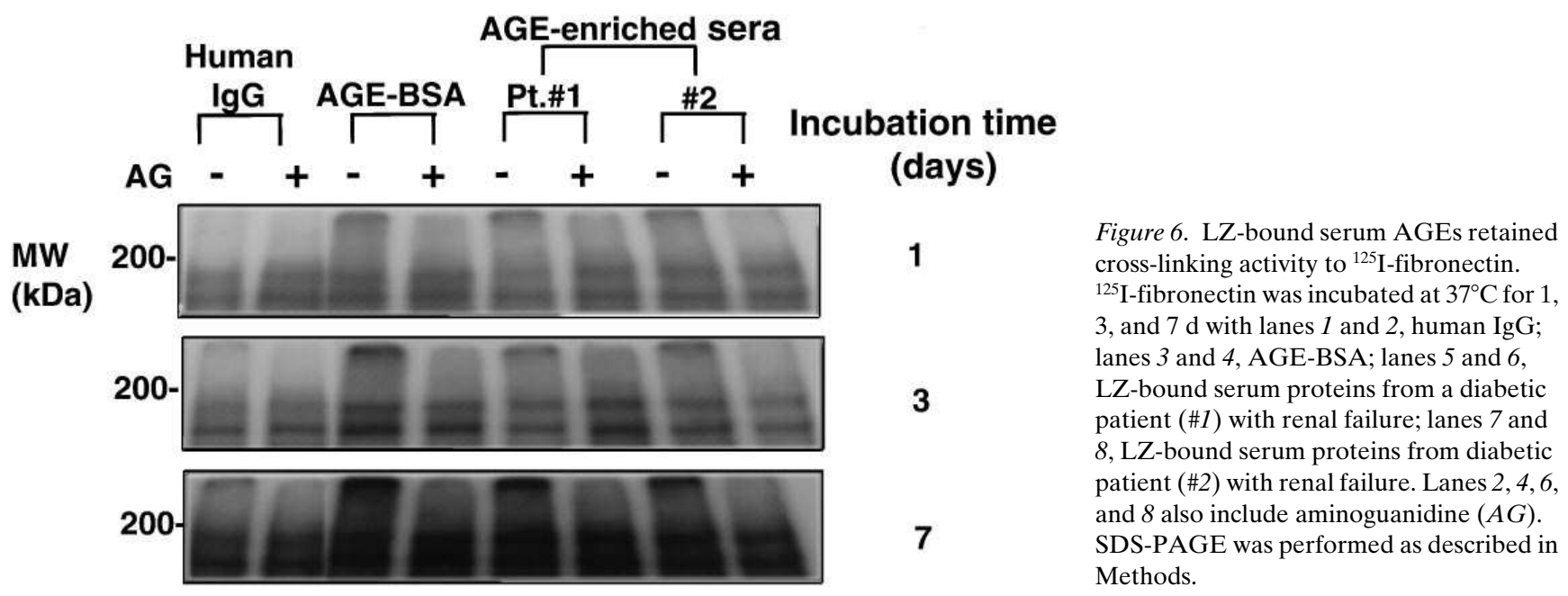

several protein databases revealed that the $\mathrm{NH}_{2}$-terminal sequences of AGE-modified 25-, 40-, and $80-\mathrm{kD}$ serum proteins are identical to the IgG light chain, apolipoprotein $\mathrm{J}$ (apoJ, clusterin/SP-40,40), and the complement $3 b$ (C3b) $\beta$ chain, respectively. Immunoblotting by antibodies to these proteins also confirmed their identities (Fig. 8, $A-C$ for $\mathrm{IgG}, \mathrm{C} 3 \mathrm{~b}$, and apoJ, $\alpha$ and $\beta$ chains, respectively).

\section{Discussion}

AGEs have been implicated in the pathogenesis of vascular and other complications of diabetes and aging $(1,3,4)$. Previous studies have shown that excessive amounts of AGEs are present in sera from diabetic and nondiabetic patients with renal failure $(5,6)$. Chemically, AGEs are highly reactive substances that participate in the cross-linking of structural proteins such as collagen and in the trapping of nonglycated proteins such as LDL and IgG (4). Such AGE modifications on proteins are irreversible and confer a high degree of resistance to proteolytic digestion (22). AGEs induce the expression of adhesion molecules (23), migration of monocytes/mac-

A

C3b $\beta$ chain
$1^{\circ}$ sequence
$2^{\circ}$ sequence
$1^{\circ}+2^{\circ}$ sequences

SPMYSIITPNILRLESEETM

SPMYSIITPXXLRLXS

XPMYSIITPNXLXLXX

B
apoJ
$1^{\circ}$ sequence
$2^{\circ}$ sequence
$1^{\circ}+2^{\circ}$ sequences

SLMPFSPYEPLNFHAMFQPFLEM

SLMPXXPYEPLNFHXMFOXF

SLMPFXPYEPXNFHAMFXPX

C
$\lg \mathbf{g}(\mathrm{L})$
$1^{\circ}$ sequence

DIVMTQVPATLSVSPGEGATLS DIVMTQXPAXL rophages, and stimulate cytokine and growth factor release from macrophages (4). Furthermore, AGEs increase endothelial permeability by disrupting cytoskeletal integrity, and increase endothelial procoagulant activity by increasing tissue factor activity and suppressing thrombomodulin expression (4). The deleterious effects of AGEs contribute to the pathogenesis of vascular dysfunction (24) and disruption of normal tissue remodeling processes (25).

"Toxic" AGE substances, along with other waste, are largely eliminated by the normal kidney, and are cleared poorly by dialysis therapies currently available to patients with ESRD (26-28). Although $\sim 20 \%$ of serum AGEs are cleared during a conventional hemodialysis session (26-28), new AGEs are generated over the ensuing 2-3 d, resulting in predialysis levels (29). High flux hemodialysis is more effective in this regard (35-40\% AGE clearance); however, the clinical application of this technology is still limited $(27,28)$, leaving kidney transplantation as the only successful intervention (26). As a consequence of the inadequacy of AGE elimination, patients with ESRD are more prone to the sequelae of the accumulation of reactive AGEs (29). Reactive AGEs may alter the
Identity to $C 3 b \beta$

$83.3 \%$

$72.2 \%$

$89.9 \%$

Identity to apoJ
-
$80.0 \%$
$80.0 \%$
$95.0 \%$

Identity to $\lg G(L)$

$81.8 \%$
Figure 7. Partial amino acid sequences and alignment of LZ-purified serum proteins. Isolation of LZ-bound serum AGEs and SDS-PAGE were performed as described in Methods. After transfer to an Immobilon-P membrane, protein bands were stained with amido black, the 25-, 40-, and $80-\mathrm{kD}$ bands were cut out, and $\mathrm{NH}_{2}$-terminal microsequencing was performed. Amino acid sequences for authentic $\mathrm{C} 3 \mathrm{~b} \beta$ chain $(A)$, apoJ $(B)$, and IgG light chain are shown with the percent homology between authentic and identified proteins. 


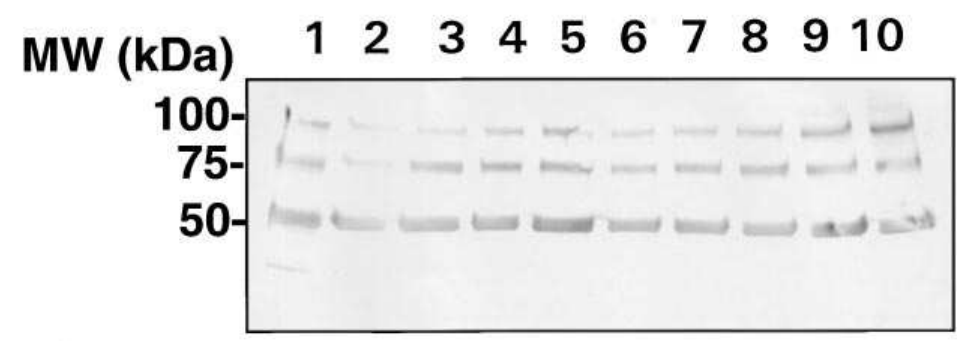

B

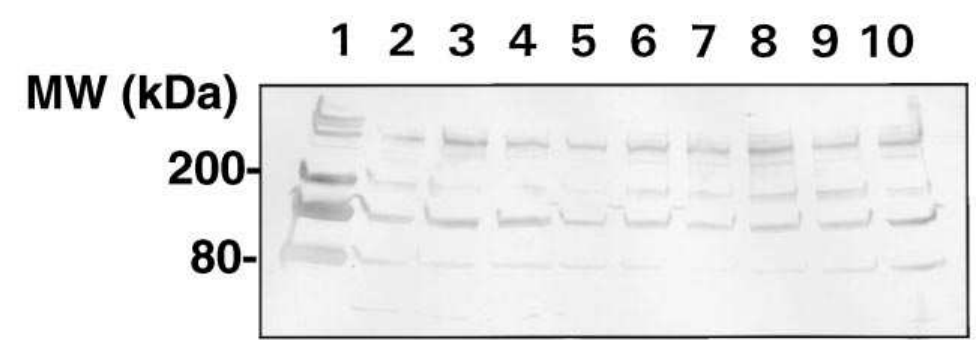

C
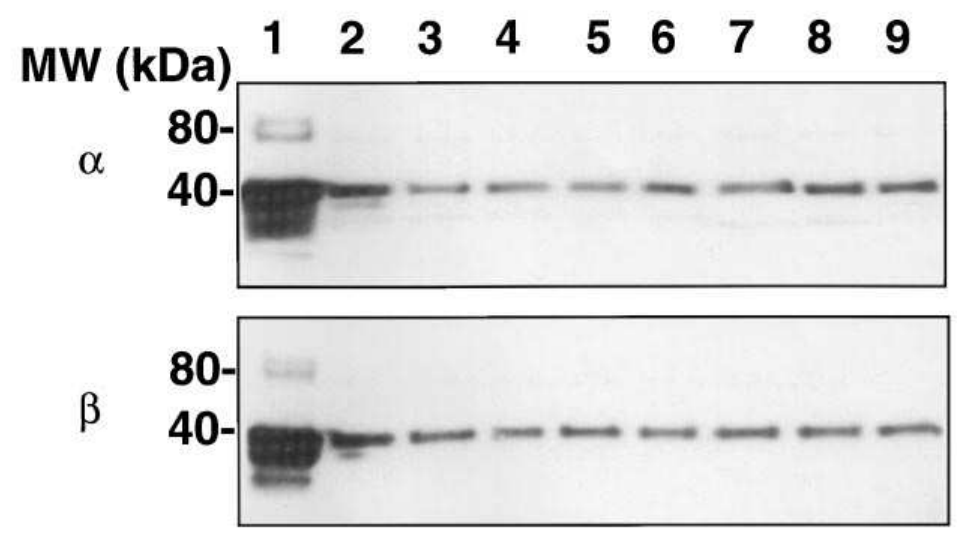

Figure 8. Immunoblot of LZ-bound serum AGEs from diabetic patients with ESRD using anti-human $\mathrm{IgG}$, anti-human $\mathrm{C} 3 \mathrm{~b}$, and anti-human apoJ ( $\alpha$ and $\beta$ chains) antibodies. Isolation of LZ-bound serum AGEs and reducing SDS-PAGE were performed as described in Methods. After transfer to a nitrocellulose membrane, immunoblotting was performed using as primary antibodies $(A)$ anti-human $\operatorname{IgG},(B)$ anti-human $\mathrm{C} 3 \mathrm{~b}$, and (C) anti-human apoJ ( $\alpha$ and $\beta$ chains). ( $A$ ) Lane 1, human IgG; lanes 2-10, LZ-bound serum AGE proteins from nine diabetic patients with ESRD; $(B)$ Lane 1, human C3; lanes 2-10, LZ-bound serum AGE proteins from nine diabetic patients with ESRD; $(C)$ ( $\alpha$ and $\beta$ ) lane 1, human apoJ; lanes 2-9, LZ-bound serum AGE proteins from nine diabetic patients with ESRD. structure and function of serum proteins and vessel wall components $(4,24,30)$, thus contributing to the accelerated vascular disease in ESRD.

To explore a potential therapeutic means to reduce serum AGE levels, we used the AGE binding property of LZ and prepared an AGE affinity LZ-linked matrix. Because LZ has the highest affinity among the AGE-binding proteins reported thus far (14), an LZ-linked matrix could prove an effective means to deplete reactive serum AGEs from uremic patients.

Our data showed that the AGE-binding activity of $\mathrm{LZ}$ is AGE specific and that unmodified serum proteins do not interfere with binding of AGE proteins to the $\mathrm{LZ}$ matrix. The LZ-bound serum proteins retain AGE immunoreactivity after being eluted from this matrix, as evidenced by two types of analysis, ELISA and immunoblot. We previously showed that the interaction between AGE-BSA and LZ was AGE specific and noncovalent; AGE-BSA binding was reversible and competitive with other AGE-modified proteins, but not with non- glycated carrier proteins or early glycation products (e.g., propylamine Amadori product), nor with glucose itself or glucosamine (14). Other experiments showed that free or proteinbound CML and pentosidine, two known AGEs (31, 32), did not bind to this LZ matrix. The critical AGE epitope(s) responsible for the binding to LZ matrix has not been identified as yet; however, our results suggest that epitope(s) other than CML and pentosidine are involved in this interaction. The LZ matrix can effectively capture AGE-modified serum proteins, as AGE levels in sera from diabetic patients with ESRD were depleted $80 \%$, whereas total protein absorption was $<3 \%$. Interestingly, the cross-linking species in the AGE-lysine preparation retrieved from the $\mathrm{LZ}$ column comprised only a small fraction $(12 \%)$ of the total fluorescence of the preparation. This suggests that monitoring fluorescence is a poor method for the quantitation of predominantly cross-linking, and thus potentially pathogenic, AGEs in biological samples.

Of particular value was the observation that the LZ-puri- 
fied serum AGE proteins remain reactive and can form complexes with other proteins assessed in our studies using fibronectin as an in vitro model structural protein. These data suggested that the LZ matrix can be used to deplete from serum the reactive AGEs that can cross-link to other proteins, such as apoB (30) and $\beta_{2}$-microglobulin (33), propagating vascular complications. Furthermore, our recent study (16) indicated that serum AGEs, isolated from patients with ESRD by the LZ-matrix method, were recognized and ingested by mouse peritoneal macrophages, which suggested that this approach may prove effective in removing from the serum AGE proteins that are capable of inducing cell activation and other adverse cellular responses through the AGE-receptor system (4, 16). Serum AGEs are considered as a newly discovered class of uremic toxins (26). In this regard, the LZ matrix appears to be a potentially valuable tool for the depletion of toxic AGEs from serum of patients with ESRD undergoing hemodialysis. Based on the data presented here, an LZ dialyzer is being evaluated for clinical application in the near future (34). Because LZ is a natural defense protein, such an LZ-matrix dialyzer should be safe for clinical application.

Among the numerous AGE-modified proteins found in the serum of patients with ESRD, we have identified three predominant proteins that appear more susceptible to AGE modification than other serum components: the $\mathrm{IgG}$ light chain, apoJ, and the $\mathrm{C} 3 \mathrm{~b} \beta$ chain. AGE modification may result in altered function of these three proteins. In vitro glycation of the $\mathrm{IgG}$ molecule can significantly lower its affinity for antigen binding, thus increasing the rate of dissociation of the antigenantibody complex (35). A significant reduction in complement fixation by glycated IgG occurs in diabetic patients $(36,37)$ and may be related to the decreased resistance to infection observed in this population. ApoJ is a sulfated, secreted glycoprotein that is ubiquitously expressed, evolutionarily conserved, and shows diverse tissue inducibility. It has been proposed to play roles in diverse biological processes, including programmed cell death (38), sperm maturation (39), complement inhibition (40), tissue remodeling (41), membrane recycling (42), and lipid transport $(43,44)$. Recently, it also has been reported that apoJ might be related to Alzheimer's $\beta$ amyloid $(45,46)$ and atherosclerosis $(47)$. Further studies will be necessary to elucidate the significance of the AGE modification of apoJ; however, the findings imply that effective prevention of the irreversible modification of such "target" proteins by AGE toxins may benefit these patients in numerous ways.

In summary, we have shown that the LZ matrix is able to significantly reduce the excessive levels of immunoreactive and cross-linking AGEs in sera from diabetic patients with renal failure. We have identified three major proteins that are susceptible to AGE modification. The LZ matrix offers a new tool for the study and treatment of the complications of diabetes or renal failure. Although further work will be necessary, using an LZ dialyzer as adjunctive therapy might be an effective way to eliminate toxic AGEs from the sera of ESRD patients.

\section{Acknowledgments}

We thank Dr. Michael Yamin for critical comments, Dr. Nam Ho Choi-Miura (Department of Physiological Chemistry, School of Pharmaceutical Sciences, Showa University, Tokyo, Japan) for kindly pro- viding anti-apoJ ( $\alpha$ and $\beta$ chains) monoclonal antibodies, Dr. Jorge Ghiso (Department of Pathology, New York University Medical Center, New York) for anti-apoJ ( $\alpha$ and $\beta$ chains) polyclonal antibodies, and Lillian M. Sellati (North Shore University Hospital, Manhasset, NY) for protein microsequencing.

\section{References}

1. Brownlee, M., A. Cerami, and H. Vlassara. 1988. Advanced glycosylation endproducts in tissue and the biochemical basis of diabetic complications. $N$. Engl. J. Med. 318:1315-1321.

2. Koschinsky, T., C. He, T. Mitsuhashi, R. Bucala, C. Liu, C. Buenting, K. Heitmann, and H. Vlassara. 1997. Orally absorbed reactive glycation products (glycotoxin): an environmental risk factor in diabetic nephropathy. Proc. Natl. Acad. Sci. USA. 94:6474-6479.

3. Brownlee, M. 1994. Glycation and diabetic complications. Diabetes. 43: 836-841.

4. Vlassara, H., R. Bucala, and L. Striker. 1994. Pathogenetic effects of advanced glycosylation: biochemical, biologic, and clinical implications for diabetes and aging. Lab. Invest. 70:138-151.

5. Mitsuhashi, T., H. Nakayama, T. Itoh, S. Kuwajima, S. Aoki, T. Atsumi, and T. Koike. 1993. Immunochemical detection of advanced glycation end products in renal cortex from STZ-induced diabetic rat. Diabetes. 42:826-832.

6. Makita, Z., H. Vlassara, A. Cerami, and R. Bucala. 1992. Immunochemical detection of advanced glycation end products in vivo. J. Biol. Chem. 267: 5133-5138.

7. Papanastasiou, P., L. Cirass, H. Rodela, A. Patrikarea, D. Oreopoulos, and E.P. Diamandis. 1994. Immunological quantification of advanced glycosylation end-products in the serum of patients on hemodialysis. Kidney Int. 46: 216-222.

8. Nakamura, Y., Y. Horii, T. Nishino, H. Shiiki, Y. Sakaguchi, T. Kagoshima, K. Dohi, Z. Makita, H. Vlassara, and R. Bucala. 1993. Immunohistochemical localization of advanced glycosylation endproducts in coronary atheroma and cardiac tissue in diabetes mellitus. Am. J. Pathol. 143:1649-1656.

9. Kume, S., M. Takeya, T. Mori, N. Araki, H. Suzuki, S. Horiuchi, T. Kodama, Y. Miyauchi, and K. Takahashi. 1995. Immunochemical and ultrastructural detection of advanced glycation end products in atherosclerotic lesions of human aorta with a novel specific monoclonal antibody. Am. J. Pathol. 147:654-667.

10. Philips, D. 1966. The three-dimensional structure of an enzyme molecule. Sci. Am. 215:78-90

11. Anderson, B., H.M. Baker, G.E. Norris, S.V. Rumball, and E.N. Baker 1992. Apo-lactoferrin structure demonstrates ligand-induced conformational change in transferrins. Nature (Lond.). 344:784-787.

12. Reiter, B., and J.D. Oram. 1969. Bacterial inhibitors in milk and other biological fluids. Nature (Lond.). 216:643-658.

13. Tenovuo, J., M. Lumikari, and T. Soukka. 1991. Salivary lysozyme, lactoferrin and peroxidases: antibacterial effects on cariogenic bacteria and clinical applications in preventive dentistry. Proc. Finn. Dent. Soc. 87:197-208.

14. Li, Y.M., A.X. Tan, and H. Vlassara. 1995. Antibacterial activity of lysozyme and lactoferrin is inhibited by binding of advanced glycation-modified proteins to a conserved motif. Nat. Med. 1:1057-1061.

15. Li, Y.M., T. Mitsuhashi, and H. Vlassara. 1995. Lysozyme enhances endocytosis of glycated proteins by macrophages. Diabetes. 44(Suppl. 1):72a

16. Li, Y.M., T. Mitsuhashi, G. Baviello, and H. Vlassara. 1996. Opsonization of removal of serum AGEs by coupling to lysozyme. Diabetes. 45(Suppl. 2):239a.

17. Mitsuhashi, T., H. Vlassara, H.W. Founds, and Y.M. Li. 1997. Standardizing the immunological measurement for advanced glycation endproducts using normal human serum. J. Immunol. Methods. In press.

18. Lowry, O.H., N.J. Rosebrough, A.L. Farr, and R.J. Randall. 1951. Protein measurement with the Folin phenol reagent. J. Biol. Chem. 193:265-275.

19. Towbin, H., T. Staehelin, and J. Gordon. 1979. Electrophoresis of proteins from polyacrylamide gels to nitrocellulose sheet: procedure and some applications. Proc. Natl. Acad. Sci. USA. 76:4350-4354.

20. Moos, M. 1992. Isolation of proteins for microsequence analysis. In Current Protocol in Immunology. J.E. Coligan, A.M. Kruisbeek, D.H. Margulies, E.M. Shevach, and W. Strober, editors. Greene Publishing Associates and John Wiley \& Sons, New York. 8.7.1-8.7.12.

21. Matsudaira, P. 1987. Sequence from picomole quantities of proteins electroblotted onto polyvinylidene difluoride membranes. J. Biol. Chem. 262: 10035-10038.

22. Brownlee, M., H. Vlassara, A. Kooney, P. Ulrich, and A. Cerami. 1986. Aminoguanidine prevents diabetes-induced arterial wall protein cross-linking. Science (Wash. DC). 232:1629-1632.

23. Vlassara, H., H. Fuh, T. Donnelly, and M. Cybulsky. 1995. Advanced glycation endproducts promote adhesion molecule (VCAM-1, ICAM-1) expression and atheroma formation in normal rabbit. Mol. Med. 1:447-456.

24. Vlassara, H., H. Fuh, Z. Makita, S. Krungkrai, A. Cerami, and R. Bucala. 1992. Exogenous advanced glycosylation end products induce complex 
vascular dysfunction in normal animals: a model for diabetic and aging complications. Proc. Natl. Acad. Sci. USA. 89:12043-12047.

25. Skolnik, E.Y., Z. Yang, Z. Makita, S. Radoff, M. Kirstein, and H. Vlassara. 1991. Human and rat mesangial cell receptors for glucose-modified proteins: potential role in kidney tissue remodeling and diabetic nephropathy. $J$. Exp. Med. 174:931-939.

26. Makita, Z., R. Bucala, E.J. Rayfield, E.A. Friedman, A.M. Kaufman, S.M. Korbet, R.H. Barth, J.A. Winston, H. Fuh, K. Manogue, A. Cerami, and H. Vlassara. 1994. Reactive glycosylation endproducts in diabetic uraemia and treatment of renal failure. Lancet. 343:1519-1522.

27. Fishbane, S., J. Maesaka, T. Mitsuhashi, G. Adam, and H. Vlassara. 1995. In-vitro clearance of advanced glycosylated endproducts (AGE) by conventional and high-flux hemodialysis (HD) membrane. J. Am. Soc. Nephrol. 6:488.

28. Fishbane, S., R. Bucala, T. Koschinsky, D. Giordano, H. Founds, and H. Vlassara. 1995. Significant reduction of plasma LDL-Apo B and glycated Apo B following chronic high-flux hemodialysis in diabetic uremic patients. J. Am. Soc. Nephrol. 6:487.

29. Makita, Z., S. Radoff, E.J. Rayfield, Z. Yang, E. Skolnik, V. Delaney, E.A. Friedman, A. Cerami, and H. Vlassara. 1991. Advanced glycosylation end products in patients with diabetic nephropathy. N. Engl. J. Med. 325:836-842.

30. Bucala, R., Z. Makita, T. Koschinsky, A. Cerami, and H. Vlassara. 1993. Lipid advanced glycosylation: pathway for lipid oxidation in vivo. Proc. Natl. Acad. Sci. USA. 90:6434-6438.

31. Ahmed, M.U., S.R. Thorpe, and J.W. Banes. 1986. Identification of carboxymethyllysine as a degradation product of fructosyllysine in glycated protein. J. Biol. Chem. 261:4889-4894.

32. Sell, D.R., and V.M. Monnier. 1989. Structure elucidation of senescence crosslink from human extracellular matrix: implication of pentoses in the aging process. J. Biol. Chem. 264:21597-21602.

33. Miyata, T., O. Oda, R. Inagi, Y, Iida, N. Araki, N. Yamada, S. Horiuchi, N. Taniguchi, K. Maeda, and T. Kinoshita. 1993. $\beta_{2}$-microglobulin modified with advanced glycation endproducts is a major component of hemodialysis-associated amyloidosis. J. Clin. Invest. 92:1243-1252.

34. Li, Y.M., T. Mitsuhashi, J. Radvich, and H. Vlassara. 1996. A novel affinity dialyzer for the removal of advanced glycation endproducts (AGEs) from the serum of dialysis patient. J. Am. Soc. Nephrol. 7:1412.

35. Kennedy, D.M., A.W. Skillen, and C.H. Self. 1994. Glycation of monoclonal antibodies impairs their ability to bind antigen. Clin. Exp. Immunol. 98: 245-251.

36. Dolhofer, R., E.A. Siess, and O.H. Wieland. 1985. Nonenzymatic glycation of immunoglobulins leads to an impairment of immunoreactivity. Biol.
Chem. Hoppe-Seyler. 366:361-366.

37. Hennessey, P.J., C.T. Black, and R.J. Andrassy. 1991. Nonenzymatic glycosylation of immunoglobulin $\mathrm{G}$ impairs complement fixation. J. Parenter Enteral. Nutr. 15:60-64.

38. Buttyan, R., C.A. Olsson, J. Pintar, C. Chang, M. Brandyk, P.-Y. Ng, and I.S. Sawczuk. 1989. Induction of the TRPM-2 gene in cells undergoing programmed death. Mol. Cell. Biol. 9:3473-3481.

39. Collard, M.W., and M.D. Griswold. 1987. Biosynthesis and molecular cloning of sulfated glycoprotein 2 secreted by rat Sertoli cells. Biochemistry. 26 3297-3303.

40. Choi, N.-H., T. Mazda, and M. Tomita. 1989. A serum protein SP-40,40 modulates the formation of membrane attack complex of complement on erythrocytes. Mol. Immunol. 26:835-840.

41. Danik, M., J.-G. Chabot, C. Mercier, A.-L. Benabid, C. Chauvin, R. Quirion, and M. Suh. 1991. Human gliomas and epileptic foci express high levels of mRNA related to rat testicular sulfated glycoprotein 2, a purported marker of cell death. Proc. Natl. Acad. Sci. USA. 88:8577-8581.

42. Palmer, D.J., and D.L. Christie. 1990. The primary structure of glycoprotein III from bovine adrenal medullary chromaffin granules. Sequence similarity with human serum protein-40,40 and rat Sertoli cell glycoprotein. J. Biol. Chem. 265:6617-6623

43. De Silva, H.V., W.D. Stuart, C.R. Duvic, J.R. Wetterau, M.J. Ray, D.G. Ferguson, H.W. Albers, W.R. Smith, and J.A.K. Harmony. 1990. A 70-kDa apolipoprotein designated apoJ is a marker for subclasses of human plasma high density lipoproteins. J. Biol. Chem. 265:13240-13247.

44. James, R.W., A.-C. Hochstrasser, I. Borghini, B. Martin, D. Pometta, and D. Hochstrasser. 1991. Characterization of human high density lipoproteinassociated protein. NA1/NA2. Identity with SP-40,40, an inhibitor of complement-mediated cytosis. Arterioscler. Thromb. 11:645-652.

45. Ghiso, J., E. Matsubara, A. Koudinov, N.-H. Choi-Miura, M. Tomita, T. Wisniewski, and B. Frangione. 1993. The cerebrospinal-fluid soluble form of Alzheimer's amyloid beta is complexed to SP-40,40 (apolipoprotein J), an inhibitor of complement membrane-attack complex. Biochem. J. 293:27-30.

46. Zlokovic, B.V., C.L. Martel, J.B. Mackic, E. Matsubara, T. Wisniewski, J.G. McComb, B. Frangione, and J. Ghiso. 1994. Brain uptake of circulating apolipoprotein J and E complexed to Alzheimer's amyloid beta. Biochem. Biophys. Res. Commun. 205:1431-1437.

47. Kleso, G.J., W.D. Stuart, R.J. Richter, C.E. Furlong, T.C. JordanStarck, and J.A.K. Harmony. 1994. Apolipoprotein J is associated with paraoxonase in human plasma. Biochemistry. 33:832-839. 